УДК 008:303.446.23

ББК 71.045

\title{
ДЕЛОКАРОВ К.Х.
}

\section{МОДЕЛИРОВАНИЕ МЕЖКУЛЬТУРНОГО ДИАЛОГА В УСЛОВИЯХ ГЛОБАЛИЗАЦИИ*}

\begin{abstract}
В статье раскрывается проблема формирования представлений о межкультурном диалоге как предмете моделирования в социально-гуманитарном знании. Автор выявляет возможности методологического обоснования значимости межкультурного диалога для будущего цивилизации; анализирует факторы, влияющие на процессы взаимодействия культур, актуализирующих научные поиски новых моделей, направленных на снижение напряженности и устанавливающих благоприятные условия для развития.

Ключевые слова: культура, глобализация, межкультурный диалог, модели и моделирование, научное знание.
\end{abstract}

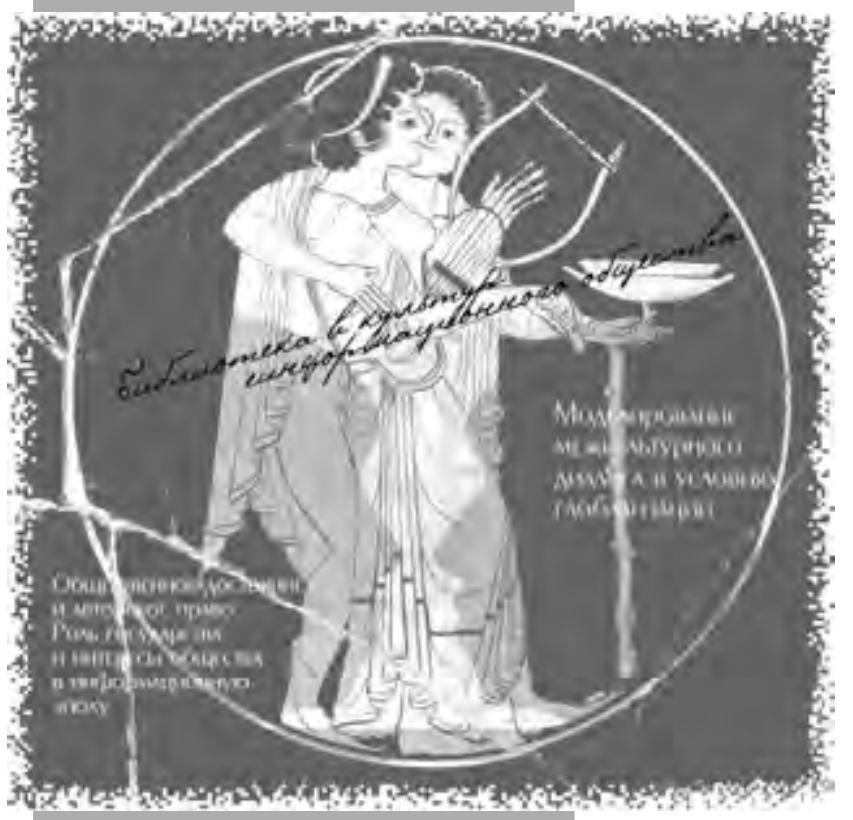

A ктуализация проблемы межкультурного диалога связана с рядом таких факторов, как: усложнение мира, вовлечение все большего числа стран, и потому людей, в мировой исторический процесс; появление новых «рукотворных» рисков (Э. Гидденс) [5], таких в частности, как глобальные проблемы современности, которые невозможно расширить без диалога культур; возрастание роли рационального начала в культуре, связанного с информатизацией общества и порожденных этим процессом новых условий бытия человека и новых смыслов.

Если кратко сформулировать те императивы, которые актуализируют проблемы межкультурного диалога, то они

\footnotetext{
“Статья подготовлена в рамках государственного задания на выполнение НИР на тему «Моделирование конструктивных практик и технологий межкультурных коммуникаций в Российской Федерации» (научный руководитель проф. 0.Н. Астафьева, РАНХиГС, 2015 г.).
}

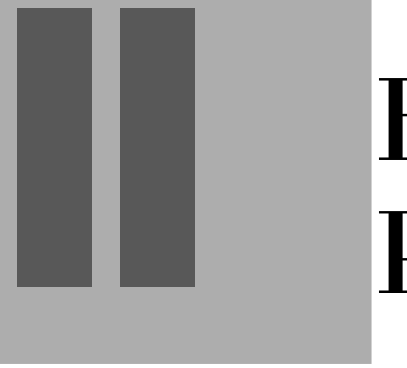

\section{КУЛЬТУРНАЯ РЕАЛЬНОСТЬ}


сводятся к тому, что процесс глобализации, резко усилив характер взаимодействия различных культур, поставил на повестку дня вопрос об умении рационально обсуждать и находить взаимопонимание между народами. В мире, где растет взаимозависимость народов, усиливаются контакты между народами, придерживающимися различных религиозных убеждений, нет иного выхода решать многочисленные проблемы, как научиться вести диалог. При этом важно, что речь идет не о диктате, а диалоге, у которого свои особенности. Упрощая, можно сказать, что не только политики и дипломаты, но и обычные люди должны проявить свои дипломатические способности, показать свою мудрость, умение слушать и слышать другого, других. Важно быть готовым к различным ситуациям и научиться жить в условиях диалога.

Принципиально значимым для будущего человеческой цивилизации в условиях динамично развивающегося глобализирующего мира является возрастание в нем роли науки и технологий в сфере культуры, как способов воздействия на качество процессов изменений. Последнее невозможно без широкого использования методов моделирования. Модель для гуманитария - это своего рода «дорожная карта», теоретическая установка, служащая основой практического преобразования реальности. При этом подобная модель - не суть жесткий алгоритм, а ценностно-мировоззренческая парадигма, которую следует творчески применять в каждой реальной ситуации с учетом ее особенностей. Несколько упростив ситуацию можно сказать, что модель не указывает единственную дорогу, а показывает общее направление развития. Поскольку сознание и знание внутренне связаны, то именно этим обусловлено влияние концептуальной модели на практику межкультурного диалога. При этом речь идет не о максималистской претензии алгоритмизации практики межкультурного диалога, а о ее общеметодологической детерминации.

Возрастание роли методов моделирования также обусловлено рядом факторов. Одним из них является резкое усложнение социальной структуры в условиях глобализации, возрастание роли человека как основного фактора многочисленных преобразований. К тому же происходит ускорение не только научно-технологического развития, но и социальных процессов, что предъявляет к человеку новые требования, связанные с умением функционировать в открытом, нелинейном мире. Таким образом, усложняется не только научно-технологический мир, но и мир культуры в целом; появляются новые модели взаимодействия, весьма противоречивые по оценке результатов такого взаимодействия [1; 2]. Отсюда актуализация проблемы межкультурного диалога и метода моделирования как инструмента не только познания, но и управления культурными процессами. Известно, что метод моделирования широко используется в науках о природе. Представляется, что он может быть продуктивен и в области межкультурного диалога.

Проблемы, которые возникают между культурами, зачастую связаны не только с тем, что происходит «здесь» и «сейчас» между этими культурами, но и уходят своими корнями вглубь истории. В процессе коммуникации, диалога можно ставить вопрос как о решении этих проблем, так и уменьшении напряженности, смягчении противоречий и подготовки благоприятной почвы, позволяющей, с одной стороны, уменьшение возможности столкновения культур, а с другой - подготовку атмосферы для более тесного взаимодействия между ними. Задача представителей социально-гуманитарной культуры - способствовать диалогу культур, дабы имеющиеся противоречия не привели к разрастанию конфликта и столкновению культур, поскольку за этим может последовать столкновение цивилизаций. При этом важно считаться со спецификой и историей различных культурных традиций, игнорирование которых не позволит понять происходящее. Последнее особенно важно для России, которая сама представляет собой своеобразную модель глобализации, поскольку в рамках российской цивилизации «встречаются» мировые религии, многочисленные нации, культуры и традиции. Не случайно именно в рамках российской цивилизации появилась философия всеединства В.С. Соловьева. В этой связи опыт межкультурного диалога в России мог бы пригодиться и в процессе поиска новых моделей глобализации.

Специально подчеркнем, что моделирование образует самостоятельный метод, который подчиняется ряду требований: во-первых, при использовании моделей важно иметь в виду, что модели не являются непосредственной копией, зеркальным отражением действительности; вовторых, используя модели мы должны решить ряд проблем, с которыми встретилось познание, и они не могут быть решены без построения моделей; в-третьих, следует считаться с тем, что любые модели - концептуальные «костыли», позволяющие ближе подойти к объекту изучения, познать его реальные свойства и законы функционирования, наконец, в-четвертых, следует помнить, что любая модель ценностно нагружена, поскольку выбор основных параметров модели делает человек, у которого имеются свои предпочтения, влияющие на построение модели.

Отметим, что речь идет не о материально-вещественных, а о культурологических, качественных моделях, опирающихся на социометрические, экономические, психологические, исторические и другие данные. При этом, поскольку культурологические модели носят качественный характер, то большую значимость приобретает учет позиции экспертного сообщества. Ценность подобных моделей в том, что они упрощают сложные процессы, существенно не влияя на результат. Отсюда их экономичность и гибкость. В процессе применения этих моделей можно варьировать различные параметры, чтобы решить поставленные задачи. Отметим также, что объектами культурологических моделей могут стать как отдельные подсистемы культуры, так и особенности функционирования ряда подсистем культуры, культурологического процесса в стране и даже в мире, если мы хотим соотнести те процессы, которые происходят, например в России, с теми процессами, которые происходят в мире. При этом эври- 
стическое «преимущество» метода моделирования еще в том, что в процессе применения моделей мы можем, в зависимости от предварительных результатов, варьировать те или иные параметры, совершенствуя качество применяемых моделей. Следующее и важное преимущество метода моделирования в том, что в процессе применения моделей мы можем получить данные о наиболее важных факторах, влияющих на изучаемое явление.

Далее сформулируем ряд опорных пунктов, образующих основание модели межкультурного диалога, способного помочь развитию российской цивилизации. Пункт первый: стратегически важно научиться использовать интеллектуальный и творческий потенциал не только отдельных городов, например Москвы и Санкт-Петербурга, но и всей огромной России; пункт второй, без которого невозможно или очень трудно реализовать первый: необходимо еще раз возвратиться в силу ее судьбоносного значения к современной образовательной системе в России и сделать ее доступной не теоретически, а практически для всего подрастающего поколения. С этой целью следует пересмотреть результаты недавней реформы образовательной системы не для того, чтобы очередной раз подвергнуть критике Болонскую систему, а чтобы сделать высшее образование в России реально доступным для тех, кто не может платить за образование, за проживание в общежитии и т. д. Образование - основа государства, и государство, в первую очередь, отвечает за доступность образования.

Из этого вытекает третий тезис: обдумать и помочь подрастающему поколению не только пользоваться новой технологией, но и эффективно функционировать в открытом информационном пространстве, жить в потоке всевозрастающей информации, не растратив своей идентичности. Моделируя будущее, мы должны считаться не только с историей страны, ее недавним и давним прошлым. Важно иметь в виду опыт как Запада так и Востока, помня, что Россия на границе этих социокультурных миров. При этом надо, на наш взгляд, не углубляясь в ставший традиционным спор «западников» и «славянофилов», исходить из реальных проблем России в области культуры, образования и науки.

Традиционная недооценка в России культурологической сферы должна быть преодолена, если страна хочет выйти на современный уровень цивилизационного развития, поскольку речь идет не только о культуре в сфере литературы, музыки, искусства и т. д. при всей их фундаментальной значимости, но и о культуре бизнеса, культуре управления и, в конечном итоге, - о культуре Человека и общества.

Отмеченные пункты - своего рода реперные точки, образующие исходные установки, которые, в свою очередь, требуют новых моделей более конкретно раскрывающих специфику других мало вовлеченных регионов.

Естественно, можно привести и ряд других положений, которые надо учитывать, но самое главное модель должна считаться с реальностью и ориентировать на «болевые» точки. Важно помнить, что Россия зачастую мыслит крайностями и сегодня можно избежать этой крайности. Если выразиться более точно, то предлагаемые меры представляют собой реакцию на проблемы, порожденные динамикой социально-политических процессов в стране. Цель модели не в том, чтобы спроектировать очередную утопию, а в том, чтобы преодолеть кризисную ситуацию. Действительное осмысление причин кризиса - необходимая составляющая движения к новой, более целостной реальности. Главная цель предлагаемых мер - открыть новые возможности для развития страны, вовлекая в процесс смыслотворчества как можно больше людей, переживающих за то, что происходит в стране.

Модели межкультурных коммуникаций можно рассматривать как подсистемы моделей социальных взаимодействий. Для российского общества принципиально важно преодолеть социальную инертность и вовлечь в межкультурный диалог как можно больше участников. Публичное участие в межкультурном диалоге будет способствовать повышению статуса и ответственности личности. Тем самым в новой ситуации начала третьего тысячелетия вновь актуализируется известный призыв И. Канта: «Имейте мужество пользоваться собственным умом без подсказки» [6]. Участники диалога в межкультурных коммуникациях становятся акторами новой реальности и тем самым вовлекаются в реальный процесс жизни.

Любые модели, в том числе и культурологические, не жестки, не алгоритмичны, и в чем-то многозначны. Однако это не недостаток, а особенность, позволяющая помочь понять законы функционирования сложных, открытых процессов, в том числе процессов, связанных с межкультурным диалогом, где приходится «работать» с неоднозначными и нечеткими понятиями. В этом отношении понятие «модель» стоит в одном ряду с такими понятиями, как «информация», «система», «симметрия» и др. [13]. Методологическая продуктивность подобных понятий как инструментов познания в том, что они позволяют «проигрывать» в мысли возможные варианты развития событий и тем самым избежать грубых ошибок или уменьшить их число. Вместе с тем, модели межкультурного диалога специфичны в том плане, в котором специфична культура, поскольку если физические или математические модели применимы везде, то эффективность моделей межкультурного диалога в значительной степени зависит от глобального контекста, истории, традиции.

Возможности межкультурной коммуникации зависят от уровня рациональной культуры участников коммуникации. Эффективность подобной коммуникации, равно как и глубина постижения участниками коммуникации целей и возможностей межкультурной коммуникации, зависит от уровня культуры участников коммуникации, их способности не только к рефлексии, но и к саморефлексии, их ценностных установок. Именно в процессе рефлексии и саморефлексии более явными становятся скрытые смыслы, которые могут стать источниками споров и взаимонепонимания. Суть актуализируемых при таком подходе проблем в том, что появляется возмож- 
ность преодоления ограниченности инструментального разума и нахождения более общей основы для взаимопонимания. Тем самым открываются новые грани рациональности и дискурса.

Дискурс, который происходит в обществе, должен носить общечеловеческий характер, не «зацикливаясь» на споре «западников» и «славянофилов» на современный манер. Любой дискурс, в том числе и культурологический, только тогда может быть продуктивным, когда он предвзят идеологически и в нем действительно заинтересованы участники диалога. Продуктивность диалога зависит от характера постановки обсуждаемых вопросов. Основной целью диалога должно стать взаимопонимание участников диалога, а только потом достижение результатов. Доминантой дискурса должно быть взаимопонимание его участников, что может привести к снятию спорных вопросов или приблизить их решения. Доминантный дискурс ориентирован на решение преимущественно общегосударственных задач. Поэтому культурологический дискурс выступает одним из «подчиненных» форм дискурса, что естественно сказывается как на тематике обсуждаемых вопросов, так и на характере обоснования доводов участников обсуждения. Подлинная же проблема в том, чтобы сделать культурологический дискурс приоритетным в обществе, что может оказать позитивное влияние на политику, экономику и другие «несущие» сферы деятельности, поскольку, в конечном итоге, действительной реперной точкой выступает человек, от знаний и ценностей которого зависит будущее общества.

Разумеется, культурологические модели как подсистема или ядро социально-экономических моделей только тогда будут эффективными, если они опираются на реальные процессы, происходящие в той или иной отрасли, которая является подсистемой общественного организма. Отсюда критика большинства культурологических моделей, пытающихся описать поведение тех или иных подсистем общества, без учета их особенностей. Все культурологические модели можно отнести в определенном смысле к смешанным моделям, поскольку они пытаются сочетать функциональные и структурные компоненты, чтобы более целостно охватить социальную реальность.

В литературе пользуются не только языком моделей, но и языком сценариев и проектов, которые близки по целевым установкам к моделям, но имеют свои характерные черты, особенно когда речь идет о межкультурном диалоге как грани, формы, а может быть ядре социального взаимодействия. Любые модели создаются для того, чтобы улучшить сценарии конкретных действий, найти те пути, которые могут помочь избежать ошибок, улучшить ситуацию. Межкультурный диалог - не самоцель, а средство решения тех проблем, которые возникают в социальном развитии. Межкультурный диалог при этом делает акцент на гуманитарных ценностях, опирается на ресурсы, связанные со знанием истории, традиции, ценностных представлениях участников диалога. Преимущество моделей межкультурного диалога в их открытости и непредвзято- сти, и их цель заключается в том, чтобы участники диалога поняли друг друга и нашли общий язык. Исследователи, моделирующие сценарии межкультурного диалога, изначально должны считаться с тем, что в культуре находят отражение процессы, происходящие не только и не столько в экономике и политике, при всей их значимости, поскольку именно здесь в духовной сфере на первый план выходят проблемы ценностей, смыслов. Далее, необходимо считаться с тем, что время жизни моделей зависит от темпов социальной трансформации, динамики ценностных оснований общества. От того, насколько эти факторы учитываются в тех или иных моделях, зависят, во-первых, их прогностические возможности, и, во-вторых, их долговечность.

Исследователи, моделирующие сценарии межкультурных коммуникаций, должны считаться с тем, что культура - «сплав» истории и современности, во время межкультурного диалога может выйти на первый план не только настоящее, но и прошлое. Именно с этим связаны трудности экстраполяции моделей межкультурного диалога из одной культуры в другую. Причина трудности - в уникальности культурных ценностей народов, исторических трансформаций. Это не значит, что между различными культурными традициями нет ничего общего, естественно инварианты есть, но в межкультурных взаимодействиях важны не только конкретные аргументы, но и контекст, который не переносится из одной культуры в другую, даже если они имеют общие черты. Ситуация осложняется тем, что человеческая история не только и даже не столько диалог культур и цивилизаций, но и их столкновение и противостояние, которые зачастую выступают фоном, а в некоторых случаях явным или неявным участником межкультурного диалога. Современного человека не может не беспокоить подобная ситуация. Он пытается жить в истории вопреки прогнозам Ф. Фукуямы [9] и избежать «столкновения цивилизаций» по С. Хантингтону [12]. Именно поэтому актуализируется вопрос о диалоге вообще и межкультурном диалоге в частности. Проблема обостряется усилением влияния постмодернистского разочарования в рациональной культуре, распространением идей терроризма на планете, усилением влияния глобальных проблем-рисков на интеллектуальную атмосферу, если отметить самые масштабные трансформации, актуализирующие проблему диалога.

Межкультурный диалог, как было отмечено, является сложным и открытым процессом, ставшим предметом проблематизации многих авторов $[3 ; 4 ; 8 ; 10]$. Как показывает история, проблема в том, что культура только тогда созидательна и конструктивна, когда она опирается на проверенные историей философско-методологические ценности, а не сводится к массовой культуре. Поэтому результат межкультурного диалога зависит от того, насколько в диалоге учитывается, говоря философским языком, не только текст, но и контекст и даже подтекст. Это необходимое условие не столько для эффективного межкультурного диалога, сколько для выстраивания прочных оснований межкультурного 
сотрудничества между участниками диалога. Естественно, что развлекательная, повседневная культура может и будет элементом межкультурного диалога, но для глубины и прочности всего здания межкультурного диалога нужен более прочный фундамент, который опирается на непреходящие философско-методологические ценности. При этом, речь, естественно, идет не о конкретных мероприятиях по межкультурному взаимодействию, а о стратегии, основаниях, которыми должны руководствоваться организаторы межкультурного диалога.

В этой связи несколько замечаний, не претендующих на оригинальность, но необходимых для обсуждаемой темы об особенностях диалога вообще и межкультурном диалоге в особенности. Во-первых, диалог - это не только умение договариваться по тем или иным вопросам, но и процесс творения новых смыслов, необходимых для решения спорной проблемы. Ведь в процессе диалога открываются новые грани, на первый план могут выйти новые вопросы, которые не могли предвидеть участники диалога. В этом плане любой диалог, касающийся сложных вопросов бытия человека, социальной группы, общества, открыт, и в процессе анализа этих вопросов могут рождаться новые смыслы. Тем самым диалог продуктивен не только для всех его участников, но и для культуры в целом: в процессе подобного диалога могут быть уточнены не только представления участников диалога, но и характер вопросов. Во-вторых, в умении договариваться, вести диалог сказывается мудрость человека, живущего в начале XXI в., поскольку он учел опыт истории и перешел от монологичности к диалогу и прошлому. Диалог - это умение не просто слушать, но и слышать другого. Поэтому умение вести диалог означает умение говорить с другим человеком, другой культурой не только на своем языке, но и на языке той культуры, с которой вы хотите договориться. Отсюда проблема понимания, как умение посмотреть на обсуждаемую проблему не только с одной стороны, но и с противоположной. В европейской культуре на необходимости диалога культур сделал акцент Дж. Локк, написавший работу о веротерпимости во время войны между католиками и протестантами [7].

Важно считаться с тем, что кто-то из участников диалога не хочет сознательно понять другого, поскольку в его нравственной системе ценностей нет того, что мы от него ожидаем. Человек может искренне не понимать, о чем идет речь. 0н может видеть и слышать другое. Поэтому требуется время, чтобы оппонирующие стороны, ведущие дискуссию, пришли к взаимопониманию.

В то же время одна из причин взаимонепонимания усложнение мира, появление новых форм сознания, например, языка, науки и широкое использование научных терминов и научной аргументации, тогда как наука - специализированный инструмент, доступный только специалистам, и ее язык понятен не всем. Этот один из факторов взаимонепонимания в современном мире относится не только к науке, но и ко многим другим явлениям и представляет собой часто проблему усложняющегося мира.
Диалог оказывается чрезвычайно важным в социально-гуманитарных науках и по той причине, что такие базовые понятия, как «общество», «класс», «социальная система», «информация», «глобализация» и т. д. имеют множество несовпадающих объяснений, создающих возможность самых разных интерпретаций тех или иных текстов.

Впрочем, это относится не только к социально-гуманитарным наукам, хотя именно в них они особенно явно проявляются. Хотя и в меньшей степени подобная неопределенность проявляется и в естественно-научных теориях. Например, такие понятия, как «объективность» и «истина» - одни из самых дискуссионных в методологии науки в целом. Диалог значительно затруднен там, где расхождения носят ценностно-мировоззренческий характер. Таким является знаменитый спор между А. Эйнштейном и Н. Бором.

В заключение отметим, что диалог возможен только в том случае, когда субъекты, участвующие в нем, способны говорить не только на своем «языке», но и на «языке» оппонента. Тем самым диалог предполагает, как отмечалось, умение слушать и слышать другого, когда участники диалога заранее исключают диктат одной из сторон. Диалог продуктивен тогда, когда есть доверие между его участниками. Таким образом, диалог - это не столько возможность говорить всем на одном языке, сколько умение наиболее «развитой» культуры не диктовать, а слушать и слышать других.

Диалог в социально-гуманитарной сфере осложняется ее спецификой. Известно, что открытость и возможность различных интерпретаций социально-гуманитарных процессов являются атрибутивной чертой социально-гуманитарных текстов. Нет ни одной социальной теории, которая бы не стала предметом споров и различных интерпретаций. Множественность различных толкований одних и тех же социальных, политических, философских и других процессов и диалог между сторонниками и противниками различных толкований этих процессов - основа, предпосылка развития личности и культуры. Именно от уровня развития личности и культуры участников, сталкивающихся в процессе дискурса, зависит диалог и глубина постижения сущего. Последнее не должно удивлять, если учесть, что в социально-гуманитарных науках нет общепринятого определения того, что такое научная теория в социологии или истории. Разногласия начинаются с понятия факта, который выступает основанием теории. Не продолжая перечень проблем, которые встают перед исследователем в данной сфере, отметим, что, в конечном счете, разногласия связаны с ценностно-мировоззренческими взглядами исследователей, хотя они не всегда проявляются. Ситуация осложняется тем, что многие понятия, с помощью которых формулируются различные социально-гуманитарные концепции, являются частью естественного языка со всеми вытекающими отсюда последствиями. Главное из последствий - возможность расхождений в толковании используемых понятий, нечеткость и много- 
образие ассоциаций, связанных с большинством неформализуемых понятий, на основании которых формируются законы, конструируются теории социологии, культурологии и подобных им наук. Все это, - а отмеченные факторы только часть проблемы, - естественный для социально-гуманитарной культуры контекст, который усложняет однозначное истолкование самых разных текстов и суждений. И поскольку «язык есть дом бытия» (М. Хайдеггер) [11, с. 266], и сам язык дает возможность различных интерпретаций не только текстов, но и поступков, то человек начала XXI в. должен быть готов функционировать в подобном мире. Это нужно для того, чтобы различать «естественные» трудности, с которыми встречаются люди в процессе диалога и «искусственные» проблемы, создаваемые его участниками, интерпретировать те или иные суждения выгодным для себя образом. Эта одна из причин возрастания роли гуманитарной культуры в будущем. Представляется, что со временем основы межкультурного диалога станут частью школьного образования.

Все эти факторы следует принимать во внимание при концептуализации и проблематизации природы и возможностей межкультурного диалога.

\section{Список источников}

1. Астафьева О.Н. Взаимодействие культур: модели и смыслы // Взаимодействие культур в условиях глобализации / под общ. ред. А.Н. Чумакова, Н.М. Мамедова. - М. : Канон + РООИ «Реабилитация», 2010. - С. 136-144.

2. Астафьева О.Н. Время антиманифеста мультикультурализма или конкуренции альтернативных моделей? // Диалог культур в условиях глобализации : XII Междунар. Лихачевские научные чтения, 17-18 мая 2012 г. - Т. І. Доклады. СПб. : СПбГУП, 2012. - С. 253-255.

3. Бахтин М.М. Эстетика словесного творчества / М.М. Бахтин. - М., 1986. - 444 с.

4. Библер В.С. От наукоучения - к логике культуры. Два философских введения в двадцать первый век / В.С. Библер. М., 1991. - 412 c.

5. Гидденс Э. Ускользающий мир = Runaway world : как глобализация меняет нашу жизнь / Э. Гидденс ; [пер. с англ. М.Л. Коробочкина]. — М. : Весь мир, 2004. - 116 с.

6. Кант И. Ответ на вопрос: что такое Просвещение? (1784) // Собр. соч. : в 8 т. / И. Кант. - М. : Чоро, 1994. - Т. 8. С. 29-37.

7. Локк Дж. Опыт веротерпимости (1667) // Соч. : в 3 т. / Дж. Локк. - М. : Мысль, 1988. - Т. 3. - С. 66-90. (Филос. наследие. Т. 103).

8. Философия в диалоге культур [Текст] = Philosophy in the dialogue of Cultures : Всемирный день философии (Москва-Санкт-Петербург, 16-19 нояб. 2009 г.) : материалы / Рос. акад. наук, Ин-т философии ; [редкол. (отв. редакторы) : А.А. Гусейнов, С.А. Никольский, Г.Б. Степанова]. - М. : Прогресс-Традиция, 2010. - 1302 с.

9. Фукуяма Ф. Конец истории и последний человек / Ф. Фукуяма ; [пер. с англ. М.Б. Левина]. — М. : АСТ : Ермак, 2004 (Тип. изд-ва Самар. дом печати). - 588 с.

10. Хабермас Ю. Моральное сознание и коммуникативное действие / Ю. Хабермас. - СПб., 2009. - 380 с.

11. Хайдеггер М. Письмо о гуманизме // Время и бытие. Статьи и выступления / М. Хайдеггер ; пер. В.В. Бибихина. СПб. : Наука, 2007. - С. 266-305. - (Серия «Слово о сущем». Т. 70).

12. Хантингтон С.Ф. Столкновение цивилизаций / С. Хантингтон ; [пер. с англ. Ю. Новикова]. - М. ; СПб. : АСТ, 2003 (Тип. изд-ва Самар. дом печати). - 603 с.

13. Штофф В.А. Моделирование и философия / В.А. Штофф. М. ; Л., 1966. - 302 c.

УДК 021.1

ББК 78.001

ЛОПАТИНА Н.В.

\section{БИБЛИОТЕКА В КУЛЬТУРЕ ИНФОРМАЦИОННОГО ОБЩЕСТВА}

Статья посвящена трансформациям социального института библиотеки в информационном обществе. Особое внимание уделено изменениям социально-гуманитарного характера. Выявлены формальные и неформальные образцы социальных отношений, роли и статусы библиотекаря. Рассматривается соответствие формально-правовых норм неформальным социокультурным нормам, реальных практик - формальным и неформальным нормам. Изучаются явные и неявные функции библиотеки, конфликт традиционных структур и новых институциональных норм. Раскрывается роль библиотекаря и читателя в происходящих процессах.

Ключевые слова: библиотека, библиотековедение, социология, теоретико-социологический подход в библиотековедении, культура информационного общества, формальные нормы библиотечного дела, неформальные нормы библиотечного дела, функции библиотеки, библиотека в социальных конфликтах, институциональные нормы, социальная аномия библиотеки. 